\title{
Analysis of Lewis Turning Point Based on China's National Conditions
}

\author{
Yu-meng YIN ${ }^{1}$, Ming $\mathrm{SU}^{2}$ and Ji-qing $\mathrm{PAN}^{3}$ \\ ${ }^{1,2,3}$ Tianjin University of Technology, Tianjin, China
}

Keywords: Lewis model, Turning point, Social phenomenon

\begin{abstract}
Lewis model is a tool for us to study the development in developing countries, it describes a process how a backward agricultural country change himself into a modern industrial nation. lewis turning point means that the country's economic structure and the labor supply will have a major turning point. Many phenomenon show that we have got the lewis turning point, however, some other phenomenon of our country get the contradictory conclusion. Under the condition of considering the lewis model implied paradox, we find that the lewis turning point has not appear in our country. Finally, the paper puts forward some Suggestions on policies in China.
\end{abstract}

It is the first time in 2004 when China's "labor shortage" phenomenon catches our attention. since that, the discuss about whether we had got the lewis turning point has never stopped coming, especially in the recent years, more and more scholar study on the lewis model. Cai Fang, one of the leading figures who hold the opinion that the Lewis point had appeared, the rising wages of "shortage of migrant workers" is just a surface of economic phenomenon, it is an essential proof of lewis turning point appeared, and he analyzed the rural surplus labor and migrant wages based on census data, finding that abundant labor supply will disappear .But Fan Gang, Wen rongqian and other scholars from short-term and structural analysis of labor supply think that lewis turning point in our country has not yet take place. Bao Xiaozhong analyzed the peasant workers' real wages income and improve the lewis model think that lewis turning point in our country has not yet take place.

\section{Analysis of the Lewis Model}

The economist William Arthur lewis, the Nobel prizewinner in 1954, puts forward the famous economic development model-the unique dual economy structure between cities and rural areas. It describes a typical dual structure of the state in the process of its industrialization, and the surplus labor in the department of agriculture continuously transfers to the city department. In 1964, Yale university economist improved of lewis model in his book "labor surplus economy development", which is the well known labor transfer model. 


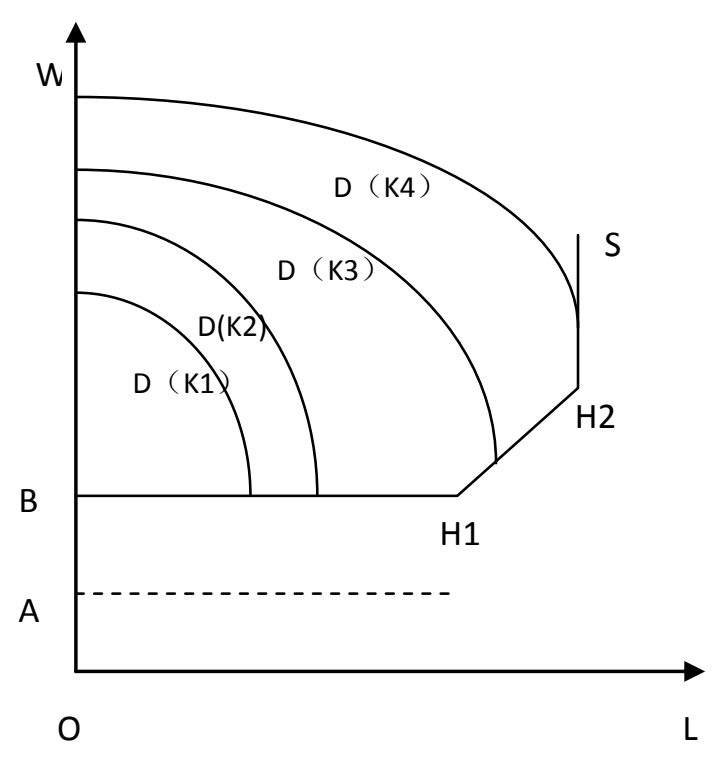

Graph 1. Lewis labor transfer model

In order to better describe the lewis model, in graph 1. The horizontal axis shows labor supply, the longitudinal axis shows marginal productivity or real wages, A shows the department wages of agriculture system, B expresses the real wages, S shows an infinite labor supply curve turning into a limited labor supply curve. A D show labor demand curve .Lewis labor transfer model is divided into three stages, the three stages was gradually arrived as time passing by. In the first stage, in the department of agriculture the land area is limited and there a large numbers of surplus labors, the marginal productivity of agriculture is zero, the system of the farmers wages is at A level, the city department of real wages is in B level. Due to B is above A, ignoring the transfer cost (such as cultural difference, the difference of customs, the discrimination, the household system, etc.), the surplus labor transfer from department of agriculture to the city departments. At this stage, the supply of labor is wireless. At the same time, the industry get further development due to absorb the transferred agricultural labor, industrial development makes the accumulation of capital increasing, the increasing demand more labor, thus caused the further transfer of the department of agriculture surplus labor, as is showed in the labor demand curve in the figure by $\mathrm{D}(\mathrm{k} 1)$ is a $\mathrm{D}(\mathrm{k} 2)$, the demand for labor moving to the right. In the second stage, due to the transfer of the agricultural sector labor force, labor supply change from the infinite supply into a limited supply, in order to city departments get more labor to raise wages to attract more of the rural labor transfer to city departments, the department of agriculture labor force also became scarce, at this time will reduce the number of department of agriculture, at the same time due to the agricultural sector labor force becomes scarce, rural per capital and resources more, department of agriculture income will be increased. System of the third stage, wage disappear completely, fully market-oriented agricultural sector labor force, surplus labor is completely released, labor supply curve into a vertical line, at this stage the rural labor force marginal productivity is the same as the city marginal labor productivity, the income of farmers reached the city level (or above city level, this is common in the United States, Japan and other developed countries, because of land as fixed assets, farmer income protection and urban workers facing unemployment risk,), dual economy into one yuan. 


\section{The Analysis of the Lewis Turning Point based on our Country's Phenomenon}

Lewis labor transfer model of the normal form of the development process as a developing country. Lewis labor transfer model make great influence, and caused a discussion of the lewis turning point. Lewis turning point, a total of two, H1 in the intersection of the first stage and the second stage, $\mathrm{H} 2$ in the intersection of the second stage and the third stage. Inflection point which is mainly discussed in our country is the first inflection point H1.The symbol usually determining whether reached the lewis turning point is the agricultural wage rates have raised sharply. Whether many scholars of our country have already reached the first inflection point, draw very different conclusions. By it is the "labor shortage" the interpretation of "exodus" and other social phenomenon appeared inconsistent phenomenon, think lewis model seems to have been the deviation in China, so we need to lewis model for further thinking.

What the "Labor shortage" and "reverse trend of heading back home" actual expressed is the agricultural sector labor supply and the agricultural sector labor oversupply situation. When the transfer of rural labor force is not enough to meet the demand of the city department of labor, there comes "labor shortage". "reverse trend of heading back home" occurs when the transfer of rural labor force is more than of the demand for labor in the urban sector .Lewis model has three implicit assumption: 1, labor are homogeneous; 2, $\mathrm{r}$ labor homogeneity of demand is in a completely free market; 3 , without considering the international situation and intensive processing enterprises transfer to other countries. However the process of the development of the three assumptions in our country is obviously not consistent.

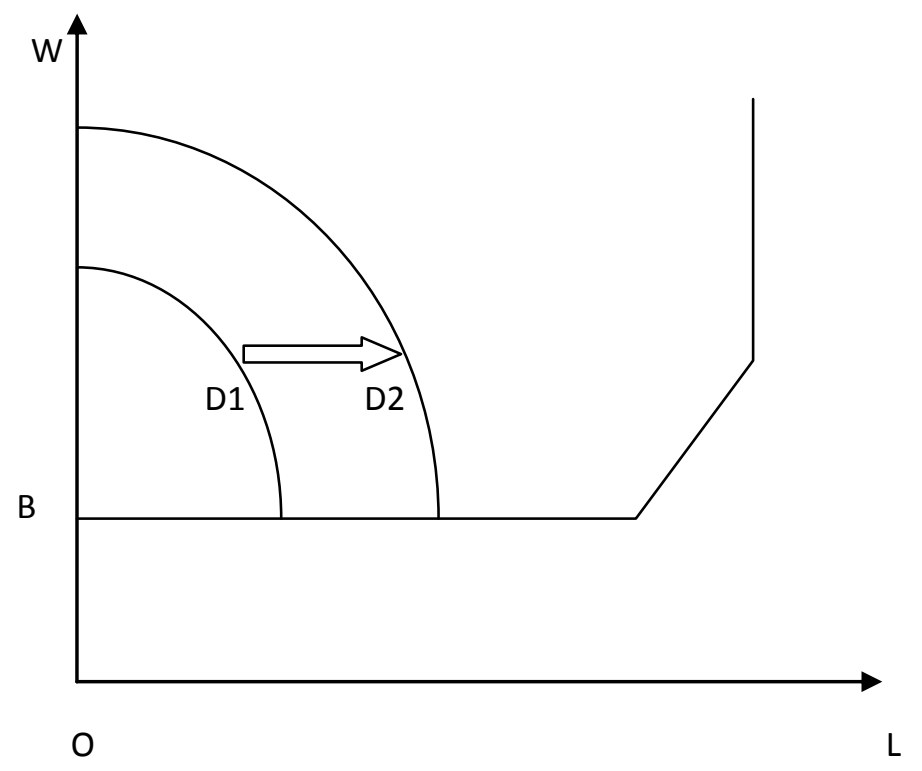

Graph 2 labor demand change under

As shown in graph 2, in the case of the government's stimulus labor, the demand curve move to the right, the government's stimulus has increased the demand for labor which makes the natural flow of labor force is not enough to meet the demand of labor, labor demand curve move from D1 to D2, resulting in a labor gap in Q2 - Q1.This will produce the so-called "labor shortage" problem, the shortage phenomenon mainly took place in 2004 and 2010, of course, the shortage of labor supply is short. Then discuss the closed economic situation, as shown in figure 3 , the global economic crisis since 2008, the weak foreign demand which makes the impact on China's 
manufacturing industry, coupled with the labor-intensive enterprises transfer to southeast Asia since 2012, it is hard to avoid resulting in a decline in demand for labor and labor demand curve by D1, D2 this will produce the phenomenon of heading back home. Agricultural sector labor supply quantity is decided by the demand of the city departments, and the "labor shortage" and "reverse trend of heading back home" phenomenon reason is complex, professor Lin by comparing the 08 years to 14 years in China and other countries find that what influences economic growth of our country in recent years lies in more externalities and periodic factors. Therefore, in the case of ignoring the government's stimulus and foreign trade environment, the discussions of the lewis turning point to as evidence we have across the lewis turning point.

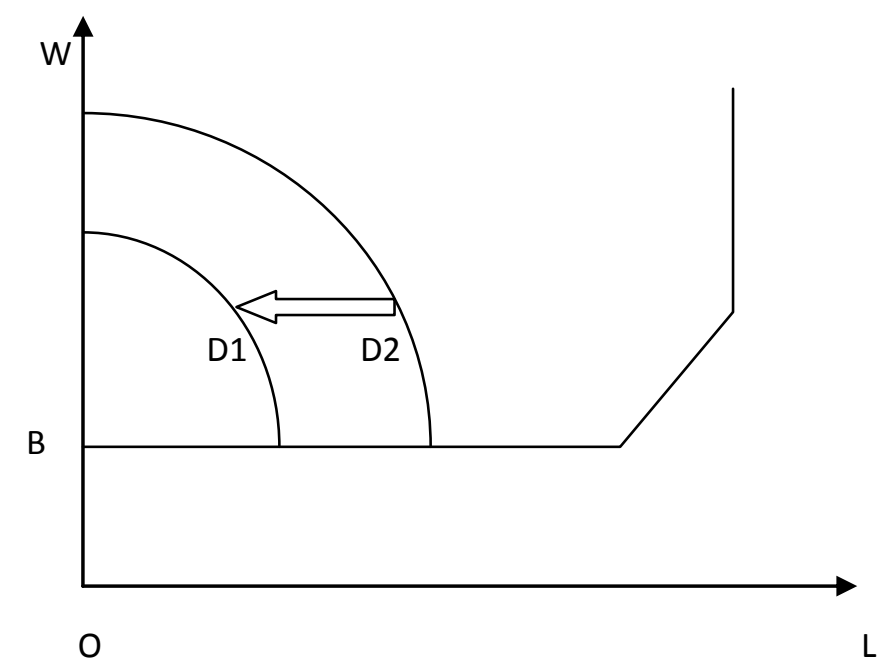

Graph 3. Transfer factory labor demand change the government's stimulus

\section{The Paradox Thinking}

From the various phenomenon of our country ,there are many proofs that show we have crossed the lewis turning point, such as "labor shortage", the improved the quality of farmers, agricultural wage rates rise, the city rising wage rates and efficiency of agricultural production, which all show we have entered the second phase of the lewis model. On the other hand, Agricultural production and rural and urban income gap, and population statistics show that our country is still in the first stage .How to understand these contradictions? First of all, lewis labor transfer model is a simplified model, it fits most especially small law of development of developing countries, however, this model is a pure closed under the market model, without considering the government function, without considering the influence of the external environment, it did not take the characteristics of the household registration system and land property right system in our country into account. In ignoring the government role, the first phase dual economic agricultural sector because there is such a large surplus labor is have no incentive to improve the production efficiency, and urban sector due to labor supply infinite rich is have no incentive to improve workers' wages. But in actual situation, the government can raise the minimum wage rate, can control the purchase price of grain, can grow subsidies to farmers, can provide technical support for agricultural production, large-scale infrastructure construction, and therefore the first stage is accompanied by the development of rural labor force transfer of synchronization. When ignore the influence of external 
conditions, foreign demand is considered to be sufficient, insufficient domestic demand in developing countries, can export of labor-intensive products rely on cheap labor advantage, it also accords with the general law of development of developing countries, foreign enough can make the capital expanding of domestic demand, until the domestic labor price no longer has a comparative advantage, but when the global economic crisis, foreign demand will be compressed, domestic capital expansion will interrupt even decline because of this, this will lead to labor transfer. And found a new cheap labor market, the domestic labor markets are bound to suffer. When ignore the household registration system and land property rights system, rural land is can under the market freedom of trade, there is neither city department of transfer of the labor force system, also do not have trouble back at home of left-behind land, household registration system and land property rights system cause inhibition to the agricultural sector labor force to cities. Lewis turning point was always supposed to be a period of change, and the government role, the international environment and characteristic system makes these lewis turning points very vague. Although it is difficult to judge which stage of lewis model we are in, but we should be sure that our ultimate objective is far distance. The good news is that the rural is still in development, unfortunately the gap between rural and urban is widening. City departments and farmers' income gap is the power of labor transfer, and the increase in the income gap in China is what we need to reflect on.

If put aside the external influence and the influence of government interference, I think our country has not get the lewis turning point. Reason 1: Lewis is essentially the rural labor transfer model capital fully market-oriented model, including the rural labor force and rural capital and rural land capital, but at present our country rural land circulation problems remain to be solved, in other words, China's rural land capital market has not been completely performed. Reason two: the registered permanent residence system restrict the flow of the labor force, exist in the labor market is not free of constraints are impossible to achieve great efficiency, we still have a method to get a further improvement, so we should abolish the household registration system. Reason 3: China's rural population quality is still very low. On the one hand, the rural population low level of education. On the other hand, in the process of labor transfer, the high quality of rural labor transfer ability is stronger, more can survive in city department to find a job, this shift as a filter always people to stay in the relatively low quality of the labor force in the rural areas, rural still do not have to attract high-quality labor conditions. Reason four: the department of agriculture and the income level of urban sector gap is widening, the department of agriculture and the income gap of urban division is the basic power of labor transfer, the widening gap between cities in the rural areas still lag behind, with the rapid development of the rural surplus labor force still. Reason 5: every year in our country there are still a large number of workers migrant from rural and urban, they live with rural household registration and not rely on land production; it shows that potential of labor transfer is huge.

\section{References}

[1] Pan Jiqing, Zhoubin, Han Guiqiang, Lina, The new conceive of the model of Chinese rural labor migration ---thinking based on short supply of migrant workers. Proceeding of the 2009 international conference on public economics and management (ICPE2009). ISBN: 978-1-846260-074-2.2009.11 
[2] J. Knight," China, South Africa and the Lewis Model”, paper Prepared for the WIDER Workshop Southern Engines of Global Growth: Focusing on Growth Experiences of China and India, Held in Beijing on January 12-13, 2007

[3] K.W. Chan, A China Paradox: Migrant Labor Shortage Amidst Rural Labor Supply Abundance, Eurasian Geography \& Economics, 2010(04), 513-531. 